\title{
As relações éticas e a imagem artística: A ética de Levinas nas imagens de Andrés Serrano
}

\author{
Ethical relations and artistic image: \\ The ethics of levinas in images of Andrés Serrano
}

por Daisy Mary da Silva Proença

\begin{abstract}
RESUMO
0 presente artigo propõe-se a pensar as relações entre ética e estética da imagem da arte, tendo por base o pensamento de Emmanuel Levinas e Maurice Blanchot, estabelecendo proximidades com o conceito de vida nua, de Giorgio Agamben, fundamentando-se também no estudo de Anita Prado Koneski, Blanchot, Levinas e a arte do estranhamento. Assim, discorre-se sobre a eticidade da imagem no que se dá como recusa de submeter-se a uma interpretação e compactuar em ser fenomenologicamente um espelhamento da realidade. 0 artigo faz uma leitura das imagens fotográficas da série The Morgue, do artista Andrés Serrano, à luz das questões apresentadas para pensar a imagem, dadas por Blanchot e Levinas. Chega-se à conclusão de que as imagens de Serrano exigem a ética de Levinas a partir do momento em que os rostos das imagens - viva expressão da vida nua - inspiram respeito e responsabilidade.
\end{abstract}

Palavras-chave Ética; Vida nua; Levinas; Blanchot; Andrés Serrano

\section{ABSTRACT}

This article intends to consider the relationship between ethics and aesthetics of the art image, based on the thought of Emmanuel Levinas and Maurice Blanchot setting close to the concept of bare life of Giorgio Agamben, basing itself also in the study of Anita Prado Koneski, Blanchot, Levinas and the art of estrangement. So, we talk about the ethics of image that gives a refusal to submit to an interpretation and a pact to be phenomenologically mirroring of reality. The article makes the reading of images from the series The Morgue, artist Andrés Serrano, in the light of the issues raised to think the picture given by Blanchot and Levinas. We reached the conclusion that the images of the Serrano require the ethics of Levinas from the moment that inspire us, those faces - living expression of bare life - respect and responsibility.

Keywords Ethics; Bare life; Levinas; Blanchot; Andrés Serrano 


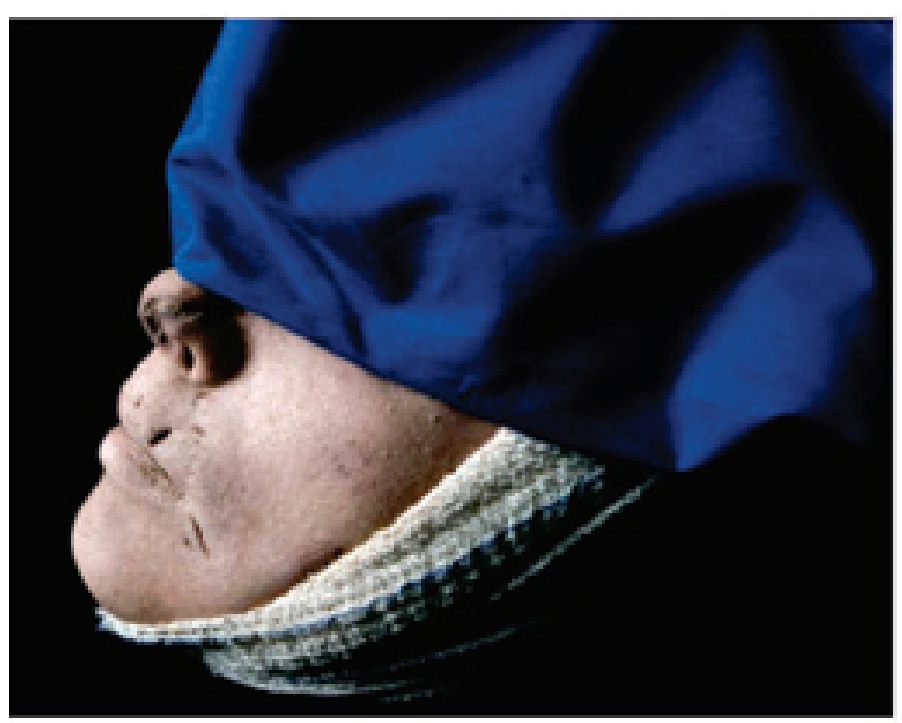

Figura 1 - Titulo: The Morgue (Killed by Four Great Denes') Data do trabalho: 1992 Meio: Cibachrome, silicone, plexiglas, e wood frame Dimensões: 125,7 X '52,4 cm

Créditos: Conteria do Artista e de Yvon Lambert Paris, Nova York Fonte: Paul Lester. Andrés Serrano Wants to be a rock Star Disponivel em: 〈www.flavorwire.com/106955〉.

Acesso em: 25 abr. 2011

\author{
OS MORTOS \\ $\mathrm{Na}$ ambígua intimidade \\ Que nos concedem \\ Podemos andar nus \\ Diante dos seus retratos. \\ Não reprovam nem sorriem \\ Como se neles a nudez fosse maior. \\ Carlos Drummond de Andrade
}

\title{
Introdução
}

Para pensarmos a ética na imagem, proposta do presente texto, faz-se necessário delinear como vamos entender e refletir sobre a questão da ética. Sabemos que a ética teve sua origem na antiguidade grega, e muitos filósofos, no decorrer do tempo estudaram, reafirmaram, propuseram e se preocuparam com relação à ética. Nosso propósito neste ensaio é pensar a ética de um outro modo de ser, e, para

1 Tradução do nome da obra: Morto por quatro grandes Dinamarqueses. 
tanto, vamos caminhar no pensamento de Emmanuel Levinas². A ética para esse filósofo nada apresenta de regras, códigos e conceitos pré-estabelecidos, nada tem de espacial ou temporal. Para ele, a ética deve ser pontuada pela responsabilidade e pela respeitabilidade diante do outro, sem que esta possa ou deva estar restrita a normas e regras morais. Na ética levinasiana, o Outro é prioridade, é o que antes subsistia como princípio privilegiador do Eu. Tendo em vista a ausência de normas e códigos a priori estabelecidos, a ética de Levinas é chamada de "ética sem ética". Levinas centra a ética na obrigação fundamental da responsabilidade infinita que não se reduz a normas morais. Trata-se de dizer, em síntese, que essa ética privilegia um tipo de compromisso existencial básico que fica definido a partir da presença do Outro como Rosto, que imediatamente nos impõe uma responsabilidade. Em Levinas, temos a ética como morada do "Outro", um lugar especial e voltado para o "Outro"3 (KONESKI, 2007).

Antes de qualquer outro aspecto, a característica mais forte da ética levinasiana é ser uma ética da alteridade, ou seja, a ética do outro. A relação ética para Levinas ocorre antes de qualquer noção ou conceito, acontece exatamente no nível "relacional-subjetivo" (MEL0, 2003). Como nos explica Melo (2003, p. 68) a estrutura da ética desse filósofo, da relação entre o Eu e o Outro, é regida por uma orientação de responsabilidade e de servilismo. 0 Outro não é propriedade minha, mas o meu próximo, que não posso matar e para o qual tiro o único pedaço de pão da minha boca para saciar sua fome. É uma relação de obrigação, de responsabilidade e respeitabilidade. Levinas (1980, p. 27) diz que “a alteridade só é possível a partir de mim", isso porque sou Eu que percebo o outro, da mesma forma que o Eu não seria o Eu sem a presença do Outro, o Eu só existe porque o outro me olha. A ética em Levinas se fixa na presença do Rosto do outro.

0 Rosto em Levinas revela a completa exposição, vulnerável à violência, mas que ao mesmo tempo "nos proíbe de matar", pois, para o filósofo, a nudez do Rosto revela sua absoluta fragilidade, e é nessa vulnerabilidade que encontramos a

2 Levinas é um pensador judeu-lituano-francês. Judeu por descendência, lituano, porque nasceu em Kauna, Lituânia, e francês, porque adotou a cidadania francesa. Levinas nasceu no dia 25 de dezembro de 1905 e morreu em 25 de dezembro de 1995. Emigrou para a França em 1923. De 1923 até 1930 estudou filosofia em Estrasburgo, participando em 1928-1929 de seminários com Husserl e com Heidegger em Friburgo, na Brisgóvia. Em 1930 doutorou-se em filosofia com a tese La théorie de l'intuition dans La phénoménologie de Husserl, obra premiada pelo Institut de France. Foi dos primeiros introdutores da fenomenologia husserliana na França, tendo traduzido, em parceria com Mlle. G. Peiffer, Méditations cartésiennes, de Husserl. 0 judeu Emmanuel Levinas foi prisioneiro em campos de concentração nazistas de 1939 a 1945, na Bretanha e na Alemanha, quando então soube que sua família tinha sido morta na Lituânia. Ensinou nas Universidades de Poitiers, Paris-Nanterre, Paris-Sorbonne. (CINTRA, 2002, p.107-117).

3 Anita Prado Koneski é formada em Artes Plásticas pela Universidade do Estado de Santa Catarina (UDESC), onde também leciona Estética no Centro de Arte (CEART), e em Filosofia pela Universidade Federal de Santa Catarina (UFSC), instituição que lhe concedeu o título de Doutora em Teoria Literária com a tese Blanchot, Levinas e a arte do estranhamento. 
responsabilidade e o respeito do Eu para com o Outro. 0 conceito de Rosto em Levinas é paradoxal, ele é simultaneamente materialidade (corpo sensível) e o que transcende essa materialidade. 0 Rosto é a face do Outro, mas o que o define especialmente é o que o transcende, no gesto, no olhar, nas ações. Assim, o que é Rosto não é o que coincide com o seu original (o corpo), com o que vejo do Outro quando estou face a face com ele, mas o que transcende esse original. Nas palavras de Levinas (1980, p. 61-62):

A nudez do rosto não é o que se oferece a mim porque eu o desvelo - $e$ que, por tal fato, se ofereceria a mim, aos meus poderes aos meus olhos, às minhas percepções numa luz que lhe é exterior. 0 rosto voltou-se para mim - e é isso a sua própria nudez. Ele é por si próprio e não por referência a um sistema.

É verdade que a nudez pode ter um terceiro sentido ainda fora do absurdo da coisa que perde o seu sistema ou da significação do rosto que rompe toda a forma: a nudez do corpo sentida no pudor, que aparece a outrem na repulsão e no desejo. Mas esta nudez refere-se sempre de uma ou de outra maneira à nudez do rosto. Só um ser absolutamente nu pelo seu rosto pode também desnudar-se impudicamente. Mas a diferença entre a nudez do rosto que se volta para mim e o desvelamento da coisa iluminada pela sua forma não separa simplesmente dois modos de 'conhecimento'. A relação com o rosto não é conhecimento de objeto. A transcendência do rosto é, ao mesmo tempo, a sua ausência do mundo em que entre a expatriação de um ser, a sua condição de estrangeiro, de despojado ou de proletário. (LEVINAS, p.61-62).

Observamos com essas reflexões que Levinas parte a sua ética do mundo vivido, no qual estabelecemos as nossas relações - o que o distancia infinitamente de Aristóteles. É aqui neste mundo vivido que me encontro com o Outro, e é nele que pesa mais do que qualquer coisa a presença do Outro, muito mais do que a do Eu. Levinas vai, com sua ética, diretamente ao Outro, esse lugar em que as indagações sobre a moral ficam sem respostas, uma vez que permanece estabelecida na ética levinasiana a infinitude do Outro. 0 outro é sempre um mistério, um abismo. Assim, não conheço definitivamente o Outro, é ético o fato de não poder chegar nele, é ética essa impossibilidade radical de ditar normas para o Outro. Se pensarmos que as normas são sempre realizadas pelo Mesmo subjugando o Outro, Levinas acolhe outra proposta para a ética, a da infinitude, a da impossibilidade, e, para tanto, centra a possibilidade de uma ética unicamente como ética da alteridade do Outro. A ética levinasiana só pode ser entendida diante do Outro, como Rosto, esse rosto que está sempre em relação assimétrica, e, por isso mesmo, ético por excelência.

Desse modo, neste ensaio, a proposta define-se em pensar a imagem como ética dentro das perspectivas levinasianas e, para tanto, entender a imagem como infinito (Rosto). A imagem da arte esteve, ao longo da história, determinada por 
regras de leitura, abordagens e funções a priori estabelecidas. Pensar a arte como um Infinito, ou seja, a partir de uma perspectiva de impossibilidade de abordagem imediata mediante regras estabelecidas, cabe a uma proposta levinasiana, porém pensamos neste artigo a possibilidade de ampliar a abordagem, aproximando 0 pensamento levinasiano ao conceito de vida nua, de Giorgio Agamben, e à imagem como infinito no pensamento de Maurice Blanchot.

Para refletir sobre a ética da imagem, na crença de que a imagem na arte funda sua própria ética quando se põe, e nesse pôr-se nos confronta e causa estranhamento, elegemos para elaborar esta reflexão as imagens fotográficas do artista Nova Iorquino Andrés Serrano ${ }^{4}$, em sua série The Morgue ${ }^{5}$ (Ver figuras 1 a 7).

As imagens desse trabalho são impressionantes e, ao mesmo tempo em que nos deixam estupefatos, atraem nosso olhar cada vez mais sedento e curioso pelo desconhecido. As imagens de Serrano apresentam, em primeiro plano, partes dos corpos de pessoas vítimas de mortes violentas, tais como suicídios, assassinatos e enfermidades fatais. A estética das composições e a obviedade dos nomes clínicos da causa mortis escolhida para títulos das obras rapidamente apagam a morbidez que talvez pudéssemos sentir. Paradoxalmente, Serrano desperta nossa empatia

4 Andrés Serrano nasceu em Nova York em 1950, filho de pai hondurenho e mãe afro-cubana, passou a infância entre Williamsburg, Brooklyn, em Nova York. Foi criado dentro de um ambiente de devoção católica, fato que desempenhou papel significativo no seu crescimento, seja em casa, na escola e nas ruas. Em razão do abandono do pai e de ter sido criado apenas pela mãe, que falava muito pouco inglês, e que muitas vezes foi hospitalizada por surtos frequentes de psicose, teve muito cedo que defender-se por si mesmo. Após uma visita ao Metropolitan Museum of Art, o jovem Serrano voltou ao local muitas vezes, encantado com as pinturas renascentistas, em particular por sua iconografia religiosa. Aos quinze anos abandonou a escola com a ambição de ser artista. Entre 1967 e 1969, frequentou o Brooklyn Museum of Art School. Sua carreira artística foi adiada por seu envolvimento com drogas e pela vida dura nas ruas pobres de Nova York. Aos vinte e oito anos, apesar de ter passado pela pintura e por uma empresa de publicidade, que 0 habilitou tecnicamente, dedicou-se à fotografia, e seu interesse não era documentar a realidade, mas sim criar sua própria realidade. Disponível em: 〈http://rogallery.com/Serrano_Andres/Andres_ Serrano-Biography.htm>. Acesso em: 11 jun. 2011.

50 nome da série fotográfica em questão, traduzida para o português, significa "0 Necrotério". Para fazer a série The Morgue, Serrano obteve autorização com um patologista/perito forense, conhecido seu, para fazer as fotografias em um necrotério sob sua jurisdição, desde que os falecidos não pudessem ser identificados em suas imagens. Como uma forma de proteger a identidade dos indivíduos, Serrano nunca revelou a localização do necrotério. Muitos dos corpos estavam lá aguardando autópsia, e Serrano não poderia trabalhar nos cadáveres antes desse procedimento, de modo a não comprometer a prova. Quando o artista chegou pela primeira vez ao necrotério, ele assistiu à autópsia de uma criança de oito anos e decidiu que teria que trabalhar rápido ou não teria equilíbrio emocional para continuar com aquele trabalho por muito tempo. 0 projeto durou três meses. Ele fotografou $95 \%$ dos corpos que chegaram lá. No início fez uma grande seção de fotos dos corpos, mas achou que as fotos se pareciam muito, eram muitas pernas e muitos troncos. Serrano revisou sua ideia inicial e passou a fotografar em close. Serrano era admirador da arte barroca, e um de seus admirados era Caravaggio, por isso a beleza de seu trabalho se deve muito a esse estilo, no que se refere à iluminação, o fundo escuro, a obliquidade da perspectiva e as narrativas enfáticas. Disponível em: ‘http://academic.evergreen.edu/curricular/imagingthebody/Handouts/DeathDyingLecture.pdf>. Acesso em: 11 jun. 2011. 
por aquelas mortes anônimas, honra aquelas vidas que se foram e que parecem renascer e eternizar-se nas perturbadoras imagens.

\section{A imagem e a dor do outro: Andrés Serrano}

Refletir sobre a ética da imagem com base no pensamento de Levinas é então, a nosso ver, entendê-la como Infinito, ou seja, como Rosto. Tal como a proposta de Levinas, o conceito de Rosto está para além da materialidade e para além do que a transcende. Iniciamos, então, nossa reflexão, dando a própria imagem da arte como Rosto. A imagem apresenta-se como materialidade, mas a transcende. Estar frente a frente com a imagem não significa poder dominá-la ou impor-lhe uma interpretação. Trata-se de dizer que a imagem não é somente o que aparece, mas o que está para além do que vemos.

As imagens da série The Morgue tornam-se a infinitude nesse frente a frente que nos leva a uma experiência de estranhamento. São muito mais do que vemos, e torna-se impossível falar desse Outro a partir do que vemos. 0 que vemos não é um correlato de algo que conhecemos, mas vai infinitamente além. As imagens dos indigentes fotografados pelo artista, em sua infinita imobilidade material, colocam-nos diante de algo mais. Como nos diz Blanchot (1987, p. 163), a imagem passa a ser a outra noite, esse lugar "onde tudo desapareceu aparece". Assim como Blanchot nos sugere uma experiência noturna, as imagens dos corpos capturados pelas lentes de Serrano também nos colocam nessa mesma experiência, pois suas imagens conservam o enigma. A experiência de olhar para essas imagens deixa nossas perguntas em suspenso, nada nos é revelado, tudo permanece na obscuridade. Os corpos, os rostos das pessoas não nos revelam as verdades de sua condição, a realidade de seus motivos, de suas tragédias, são esta outra noite, descrita por Blanchot, "que não acolhe e não se abre", e, deste modo, permanecemos sempre do lado de fora.

Blanchot (1987, p.169) afirma que "a outra noite é sempre o outro", no sentido de mistério, quando a realidade da existência se torna estranha por estar completamente distante de ser um correlato da realidade e, por esse motivo, 0 artista transforma essa realidade em arte. Podemos dizer, então, que a realidade dos necrotérios é por si mesma esse estranhamento, um lugar obscuro, ou a própria obscuridade da qual falam as imagens da série The Morgue. É nesse sentido que podemos entender a obra, como um mistério, não apenas para nós, mas até mesmo para o artista. A outra noite, a criação do mistério, a conquista do obscuro é a questão essencial dessas imagens de Serrano. Tanto em Blanchot como em Levinas, encontramos o pensamento de que a obra de arte só é obra à medida que realiza o enigma, que se faz mistério, ou seja, quando conquista do obscuro.

As imagens de Serrano, a nosso ver, seguram esse sussurro, esse mistério, o enigma da outra noite, da qual fala Blanchot. Ao expor a questão da obscuridade, 
Blanchot afirma no sentido de podermos ler o espaço poético, o mundo, a realidade e o Outro de uma outra forma que não seja essencialmente pela clareza, pela razão pura e simples. Nas imagens de Andrés Serrano, podemos perceber isso, não podemos usar a clareza para realizar uma leitura. Mas podemos dizer com Blanchot (1987, p. 168) que Serrano pauta sua poética na outra noite a que se refere Blanchot (1987, p.168), criada na vivência, na existência, na vida, ou seja, o artista elabora a sua arte aqui, na vida cotidiana, mas esta só se faz infinitude quando se torna a outra noite, quando conserva o mistério e deixa-nos desejosos desse mistério. Andrés Serrano, a nosso ver, constrói as suas imagens no cotidiano do necrotério. A escolha dos personagens mostra a realidade daquele lugar, mas, apesar disso, conserva tais imagens distantes da luminosidade da leitura, até mesmo longe da temporalidade que dá conta de si - o mistério, a essência, que nos mantêm na obscuridade.

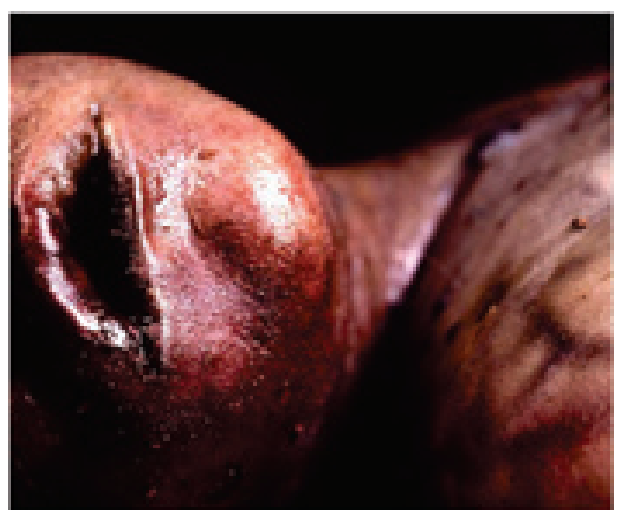

Figura 2 - Título: The Morgue (Knifed To Death $\mathrm{I}^{6}$ ). Artista: Andrés Serrano. Data do trabalho: 1992. Meio: cibachrome, silicone, plexiglas, wood frame. Dimensão: h 49,5 X w: 6oin h: 125.73 x w: $152.4 \mathrm{~cm}$. Créditos: Courtesia Paula Cooper Gallery, New York Fonte: Artnet'auctions. The Morgue Disponivel em: < www.artnet.com/usernet/ awc/awc>. Acesso em: 25 abr. 2011

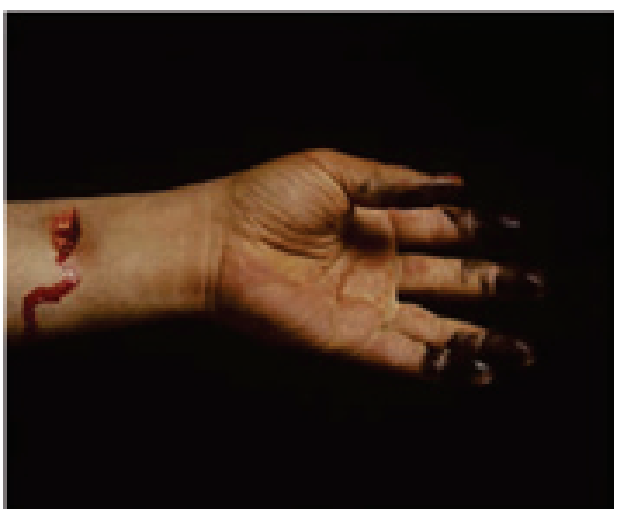

Figura 3 - Título: The Morgue (Death by Drowning $I^{7}$ ). Artista: Andrés Serrano. Data do trabalho: 1992. Meio: Cibachrome, silicone, plexiglas, wood frame. Dimensão: h:125,73 x w: 152,4 cm. Créditos: Cortesia Paula Gallery, New York. Fonte: Artnet'auctions. The Morgue. Disponivel em: 〈www.artnet.com/usernet/awc/awc〉. Acesso em: 25 abr. 2011

As figuras dramáticas dessa série são recortadas sobre fundo escuro, o que faz ressaltar os rostos ou partes do corpo escolhida pelo artista, seus tons marmóreos, evidenciam detalhes faciais e de partes do corpo com fria exatidão. A escolha e o interesse anatômico, o contraste entre vermelhos, roxos, azuis, brancos e negros, o estado estático das imagens, estas congeladas em um movimento eterno, são apresentados de forma contundente por Serrano. No realismo das imagens

6 Tradução do nome da obra: Esfaqueado até a morte I.

7 Tradução do nome da obra: Morto por afogamento II. 
sentimo-nos em uma situação antagônica, ora elas nos causam mal-estar, ora, ao contrário, podemos dizer que há um certo encantamento. Tais imagens instituem-se como vestígios de algo que está como excesso para nosso conhecimento. As imagens das pessoas mortas murmuram toda crueza da condição humana. Mas sabemos que essas imagens não compactuam totalmente com a realidade, elas vão muito além e se instalam num Infinito, lugar do estranhamento.

A relação ética com essas imagens está para além de qualquer representação. É quando entendemos que a ideia de Rosto está para além da sensibilidade, embora esteja nela e com ela, uma significação inapreensível. Sybil Sadie Douek (2011), referindo-se à ética do Outro em Levinas, diz que

Outrem não se apresenta para mim como um objeto que posso prender em minha compreensão, do qual posso dispor reduzindo-o ao meu saber sobre ele: a presença de Outrem me ultrapassa, me transcende, me abre para o Infinito; a partir de sua aproximação, Outrem me põe diante de seu Rosto. (DOUEK, 2011, p. 157).

Os rostos fotografados por Andrés Serrano nos confrontam. Olhar para eles nos coloca também diante do Rosto do Outro, diante de nosso próximo, diante da condição em que se encontram essas pessoas. 0 Outro exige de mim a respeitabilidade inferida pela ética levinasiana mediante a imagem, sendo a própria imagem a instaladora dessa ética, quando não se submete a ser correlato da realidade e infere algo de mistério que está para além dela. A imagem cobra uma postura ética quando nos põe diante da infinita dor do outro, e devemos entender que isso se realiza na imagem, ou seja, o que não consigo entender, o que vai além de meu entendimento é proeza da imagem na sua realização. Trata-se de dizer que a imagem não permite uma interpretação, ou melhor, não permite ser subordinada a uma interpretação, e, assim, põe a dimensão infinita da dor, ou seja, o que jamais será possível abraçar. Acolho a imagem, então, na ideia de Rosto e de respeitabilidade dada por Levinas.

As imagens de Serrano exigem a ética do Outro pela extrema "nudez" dos rostos cadavéricos em toda sua vulnerabilidade. Elas exigem essa ética mediante suas faces marmóreas em toda a estranheidade, em toda a sua linguagem que não se deixa dizer. A imagem impõe sua força e, por detrás da extrema palidez daqueles rostos e da angústia que nos causam, torna a sua exigência de respeito e responsabilidade ainda mais gritante. Atribuímos às imagens de Serrano a força ética que é gerada no contato do olhar que interroga e na imagem como excesso. Torna-se a obscuridade do estranhamento, gerado pela vida do Outro que ali se esvai como vida nua. 0 excesso da imagem está no fato de que tudo o que ali vemos está "para além" da nossa possibilidade de interpretação. Segundo Levinas, esse "para além" não se funda pelo distanciamento, mas pela forte proximidade de nossa humanidade, ou seja, é tão humano o que vemos, tão demasiado humano, que não conseguimos dizer. Tudo o que ali está nas imagens é extremamente humano. A obscuridade é a morada das imagens fotográficas de Serrano. 
Do Outro de Andrés Serrano, ali feito imagem, podemos até "ouvir a sua miséria que clama justiça" (LEVINAS, 1980, p. 193), por aquelas mortes prematuras e violentas, sejam por assassinatos, por suicídios, ou até mesmo por enfermidades fulminantes. Porém, esse ouvir não nos chega pelas vias da interpretação, da compreensão e leitura da imagem, mas pela dificuldade radical que temos de acolhê-la como algo que podemos dar conta. 0 ser que nos é apresentado na imagem "vem de uma dimensão de altura, dimensão da transcendência" (LEVINAS, 1980, p. 193), em que o Eu se coloca na posição de "responder à miséria essencial" (LEVINAS, 1980, p. 193) desse Outro que está diante de nós. 0 apelo ético dessas imagens nos conduz à verificação da vulnerabilidade e nudez do Rosto a que se refere Levinas.

As imagens fotográficas de Serrano expõem o Rosto tal qual nos infere a ética levinasiana, ou seja, evidenciam a relação entre o Eu e o Outro totalmente outro. 0 Outro naquelas imagens, que por vezes mostra o rosto e por vezes partes diversas do corpo, que evidenciam a causa mortis, pede de nós a devida reverência às suas vidas perdidas de forma brutal e esquecidas de forma inumana, nos necrotérios. Esses rostos lívidos impõem a reformulação do conceito de humanidade, de poder sobre a vida do Outro, toda a linguagem e toda a temporalidade ética. 0 Outro e 0 eu são absolutamente diferentes, e é dessa diferença absoluta que deveria proceder o dizer quando pensa em definir o Outro. Levinas diz que "o rosto do outro se recusa à nossa posse, aos nossos poderes" (1980, p.176).

Os rostos dos corpos que Serrano fotografa se oferecem ao nosso olhar, mas mantêm a recusa à posse e ao poder, mantêm a eterna recusa ao nosso conhecimento. 0 que fazer com aquele Rosto que, por sua simples presença, atesta a impossibilidade de matar, mas que se revira em responsabilidade pela morte e vida de outrem? "A epifania do rosto é ética" (DOUEK, 2011, p.161). Tudo de tal modo que aquela morte anônima ali estampada na imagem seja radical responsabilidade minha e assunto meu.

\section{A "Vida Nua" nas imagens de Andrés Serrano}

0 Rosto, então, nas imagens de Serrano, coloca-nos em contato direto com os vestígios, a obscuridade, que podemos aproximar do conceito de "vida nua", a qual se refere Agamben (2010). A vida nua, conceito desenvolvido por Agamben (2010), tem diante de si a experiência extrema dos excluídos e relegados aos campos de concentração nazista da Segunda Guerra Mundial. 0 homem nessa situação foi destituído de seus direitos fundamentais, por força da política, por ato da Totalidade, que desconhece a diferença, tendo sido relegado, ao que Agamben chama, de vida nua. A exclusão para Agamben entra como uma exceção à regra, exceção essa que passa a ser a regra, porém ele aponta que esse acontecimento - a exclusão - não é apenas registrado naquele momento da história, mas é uma constante na biopolítica moderna. Agamben (2010, p. 116-117) constrói esse conceito com 
base no conceito de biopolítica foucaultiana. 0 conceito de Foucault fala que na sociedade há uma fronteira de modernidade biológica quando a espécie e o indivíduo, como simples corpos viventes, tornam-se o ponto nevrálgico das estratégias políticas modernas. Sobre o conceito de biopolítica de Foucault, Agamben o pensa dentro do ponto de vista dos campos de concentração, apontando para "a radical transformação da política em espaço da vida nua" (2010, p.117) e destacando uma certa animalização do homem.

No sentido de que aquilo que caracteriza a política moderna não é tanto a inclusão da zoé na polis [...] decisivo é, sobretudo, o fato de que, lado a lado com o progresso pelo qual a exceção se torna em todos os lugares a regra, o espaço da vida nua, situado originalmente à margem do ordenamento, vem progressivamente a coincidir com o espaço político, $e$ exclusão e inclusão, externo e interno, bíos e zoé, direito e fato entram em uma zona de irredutivel indistinção. (AGAMBEN, 2010, p.16).

A realidade dos necrotérios é abrigar corpos de pessoas mortas, aparentemente sem identidade, para que posteriormente sejam resgatados e reconhecidos por seus familiares ou conhecidos, porém o que mostra Serrano com aqueles corpos aparentemente anônimos é que estes permanecerão eternamente anônimos, assim como anônimos também ficaram os corpos "viventes" e "sacrificados" nos campos de concentração nazista - dos quais fala Agamben - sob o conceito de vida nua, pois são vidas classificadas como Zoé (vida vulgar, vida animal), enfim, corpos sob a condição de exceção.

0 que era íntimo passa a ser público, o que era particular passa a ser exposto, de modo que todos possam ser de certa forma, reduzidos a uma vida nua, desprovida de todo direito. Pessoas, que na condição de excluídas do contexto político e social ao qual outrora haviam pertencido, foram jogadas naquele lugar como vítimas de assassinatos, suicídios ou doenças que usurparam a vida daqueles corpos de forma violenta e brutal. Pessoas que se suicidaram, talvez num limite extremo da dor social, moral, ou até mesmo física, pessoas assassinadas talvez com crueldade, vidas ceifadas por doenças graves, e que, uma vez capturadas pelas lentes de Serrano, são eternizadas no tempo e no espaço daquele momento derradeiro. É cruel talvez pensarmos que aqueles rostos fotografados na sua condição de momento permanecerão para sempre em sua imobilidade, sabendo-se que já não existem mais.

Os rostos que mostram as imagens de Serrano não são, na realidade do necrotério, nada mais que um corpo desprovido de vida e, na maioria das vezes, de um nome, vidas nuas, que nem vidas são mais. São, na verdade, morte em movimento infinito. Parece contraditório pensar em movimento diante da imobilidade mortal, mas a cada nova mostra da série The Morgue, essas mortes movimentam-se nos olhos e no estranhamento de cada novo espectador. Continuam vidas nuas, porque esses corpos permanecerão sempre presentes nas imagens do artista, mostrando suas misérias, mas continuarão em uma constante situação de exceção, pois a 
regra é a de que esses corpos, após algum tempo, na condição de cadáveres, “desapareçam" dentro da condição natural de um corpo sem vida. Essas imagens de Serrano nos atiram em um abismo, na extrema angústia diante do inominável, da impossibilidade. Elas fundam uma ética, colocam-nos num compromisso mudo de responsabilidade e respeito por aquelas vidas que transcenderam a vida.

Agamben (2010, p.132) aprofunda o conceito de vida nua quando expõe e comenta o conceito de Karl Binding8 sobre a "vida que não merece viver ou indigna de ser vivida". Binding elabora uma teoria para justificar juridicamente o suicídio e a eutanásia, que entram na condição do nacional-socialismo, como uma questão de limpeza genética, purificação da raça. Induz o pensamento de que o suicídio é um ato de soberania do homem vivente sobre a própria existência, porque o suicídio não pode, do ponto de vista jurídico, ser considerado um delito, pois que é um ato soberano do vivente sobre sua própria existência. Mas, por outro lado, também não pode ser excluído ou incluído, nem vetado e nem mesmo permitido dentro de uma ordem jurídica. A consideração de Binding a respeito do conceito de "vida indigna de ser vivida" é encontrar um argumento jurídico para justificar e permitir 0 aniquilamento impune de vidas humanas quando estas, segundo ele, "perderam a tal ponto a qualidade de bem jurídico, que a sua continuidade tanto para 0 portador da vida como para a sociedade, perdeu permanentemente todo o valor" (1920 apud AGAMBEN, 2010, p.133). Segundo Agamben, Binding não vê razão, nem de cunho "jurídico, nem social, nem religioso, para não autorizar a morte destas pessoas. Que não são mais do que a espantosa imagem, ao avesso, da autêntica humanidade" (AGAMBEN, 2010, p.134). Binding, conforme fala Agamben, parte do princípio de que a autorização para o aniquilamento deva ser de iniciativa do próprio doente (aqui pensamos como suicídio), ou de um médico ou de um parente próximo (aqui pensamos como assassinato), mas que a decisão final ficaria a cargo de uma comissão composta por um médico, um psiquiatra e um jurista. Para Agamben, o mais interessante "é o fato de que à soberania do homem vivente sobre a sua vida corresponda imediatamente a fixação de um limiar além do qual a vida cessa de ter valor jurídico e pode, portanto, ser morta sem que se cometa homicídio" (AGAMBEN, 2010, p.135). Embora essa nova categoria jurídica aparentemente não caminhe na mesma direção que a "vida nua e a do homo sacer", pode ser entendida para além dos limites pensados por Binding (AGAMBEN, 2010, p.135).

8 Karl Binding jurista especialista em direito penal. BINDING, Karl; HOCHE, Alfred. Die Freigabe der vernichtung lebensunwerten Lebens. Leipzig: [s.n.], 1920.

9 Homo sacer, quer dizer homem sacro, é uma figura do direito romano arcaico. Festo acrescenta ao seu verbete sobre Monte Sacro (sacer mons), que: "Homem sacro é, portanto, aquele que o povo julgou por um delito; e não é lícito sacrificá-lo, mas quem o mata não será condenado por homicídio; na verdade, na primeira lei tribunícia se adverte que 'se alguém matar aquele que por plebiscito é sacro, não é considerado homicida'. Disso advém que um homem malvado ou impuro costuma ser chamado sacro." (AGAMBEN, p.74, e notas do tradutor n.18, p.186). 
É como se toda valorização e toda 'politização' da vida [...] implicasse necessariamente uma nova decisão sobre o limiar além do qual a vida cessa de ser politicamente relevante, é então somente 'vida sacra' e, como tal, pode ser impunemente eliminada. [...] A vida nua não está mais confinada a um lugar particular ou em uma categoria definida, mas habita 0 corpo biológico de cada ser vivente. (AGAMBEN, 2010, p. 135).

Essa condição de suicídio/eutanásia existiu dentro da política do nacional-socialismo para justificar as mortes dos "diferentes", por isso Agamben diz que, sob a aparência de um problema humanitário, a eliminação dos doentes incuráveis, mentais e com defeitos físicos estavam dentro do horizonte da nova vocação biopolítica do Estado, do poder soberano de decidir sobre a vida nua.

Essas questões também estão, a nosso ver, (e vemos proximidade), com as imagens da série The Morgue do artista em questão. Aquelas mortes mostradas, tão explicitamente, de pessoas que sofreram agressões que as levaram à morte, podem ser comparadas com a questão da "vida que não merece ser vivida", quando era recomendada a "eutanásia", que naquele contexto estava completamente próxima de um assassinato. Para Levinas, "somos todos responsáveis", e Andrés Serrano, então, mostra de forma ostensiva a vida nua que habita cada corpo biológico. As imagens da série The Morgue nos trazem também a questão do suicídio, que é um ato sem justificação jurídica, mas que é um ato decorrente de um desajuste, seja ele moral, social ou pessoal. Não importa qual a razão do desajuste, o que nos importa nesse momento são aquelas vidas perdidas, aquelas vidas nuas, que são responsabilidade nossa, já que somos membros dessa sociedade que oprime, que cobra, que reivindica uma atitude, uma maior integração.

As imagens de Andrés nos colocam em uma posição de algozes dessas vidas que aparentemente foram consideradas em algum momento "vidas que não merecem ser vividas", como parte dessa mesma sociedade que gerou, criou e educou 0 dono daquela mão assassina, que, talvez, se questionado, tivesse inúmeros argumentos para justificar seu ato, assim como o fez o jurista "tentando" enquadrar dentro da lei um ato bárbaro como a indução ao suicídio e o ato de decidir quem deve viver e quem deve morrer.

As imagens de Serrano nos aproximam da discussão elaborada por Agamben e a ultrapassam pela força com que as imagens nos atingem e nos colocam diante da responsabilidade por aquelas mortes. Aqui mais uma vez vamos ao encontro da ética de Levinas no que se refere à responsabilidade e ao respeito pelo Outro, diante da imagem que se faz ética ao não pertencer a uma leitura por adequação, ajustada, mas por inferir todo mistério da morte. 


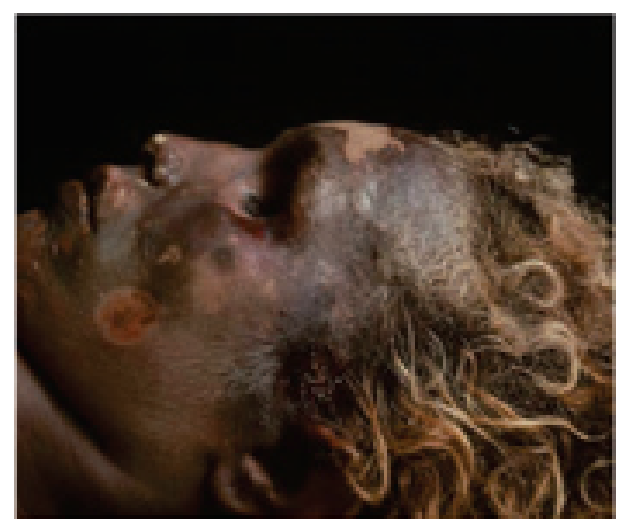

Figura 4 - Título: The Morgue (Jane Doe Killed by Police $\left.{ }^{10}\right)$. Data do trabalho: 1992. Meio: Cibachrome, silicone, plexiglas, wood frame. Dimensões: $125,73 \times 152,4$ $\mathrm{cm}$. Créditos: Cortesia de Paula Cooper Callery, New York. Fonte: Artnet'auctions. The Morgue. Disponível em: «www.artnet. com/usernet/awc/awc>. Acesso em: 25 abr. 2011

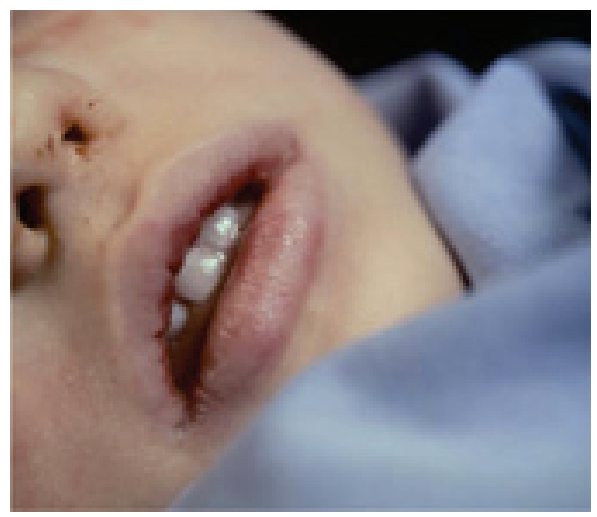

Figura 5 - Título: The Morgue (Pneumonia Due To Growning"1 II). Data do trabalho: 1992. Meio: Cibachrome, silicone, plexiglas, wood frame. Dimensões: 125,73 X 152,4 cm. Créditos: Cortesia de Paula Cooper Gallery, New York. Fonte: Artnet'auctions. The Morgue. Disponível em: 〈www.artnet.com/usernet/awc/awc〉. Acesso em: 25 abr. 2011

\section{Em busca de uma ponderação final}

Diante da proposta de considerar a imagem como um espaço em que se dá o encontro entre o estético e o ético, abrimos um lugar de reflexão no âmbito existencial com base em Levinas, Blanchot e Agamben. Propomos, dessa maneira, pensar que a ética de Levinas nos é exigida nas imagens de Andrés Serrano, mediante aqueles rostos e corpos, expressão da vida nua. 0 Outro ali exposto pela imagem recusa-se ao meu conhecimento e permanece o absolutamente Outro. Segundo Levinas (2001), esta é a propriedade essencial da imagem, pois não me é possível ditar as regras de leitura (interpretação) para o que vejo nas imagens, elas nos desconcertam e nos jogam em um abismo infinito, mantendo-nos na obscuridade, enfim, são muito mais que a realidade. As imagens de Serrano nos ensinam que ética não é ter domínio sobre o outro (e nesse caso o outro é a imagem), mas é perceber, é estar diante da dor do outro sem que com isso tenhamos que explicar, tematizar, dar o testemunho do entendimento. A ética levinasiana nos conduz para uma respeitabilidade e para uma responsabilidade, sem equivalência, para com o Outro. Assim, a nosso ver, é esse respeito e essa responsabilidade que as imagens de Serrano nos propõem e nos cobram, reivindicam e exigem quando olhamos

10 Tradução do nome da obra: Jane Doe morta pela polícia.

11 Tradução do nome da obra: Pneumonia dupla cultivada II. 


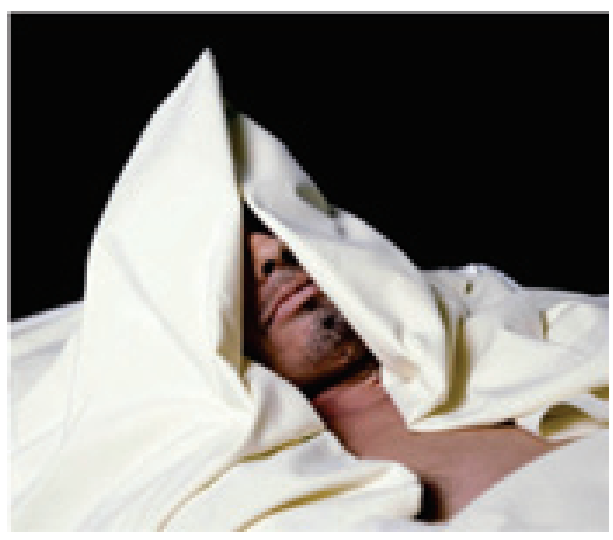

Figura 6 - Artista: Andrés Serrano. Andrés Serrano Título:The Morgue (Death Unknown'12) 1992. Cibachrome, silicone, plexi-glass, wood frame. Dimensão: 49 1/2 x 60 inches.Créditos: Cortesia do artista e Yvon Lambert Paris, New York. Fonte: Paul Lester. Andrés Serrano Wants to be a rock Star. Disponível em: «www.artnet.com/ usernet/awc/awc> Acesso em: 25 abr. 2011

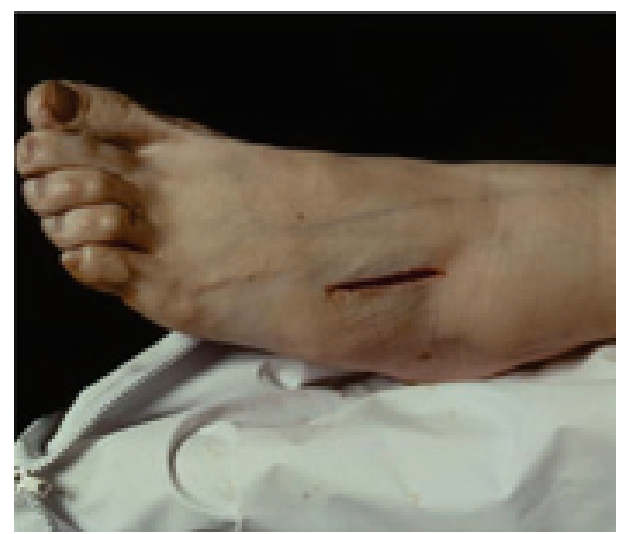

Figura 7 - Artista Andrés Serrano . Título: The Morgue (Rat Poison Suicide ${ }^{13}$ II), 1992. Meio: Cibachrome, silicone, plexiglass, wood frame. Dimensão: h: 125,73 X 152,4 cm. Créditos: Cortesia Paula Gallery, New York. Fonte: Artnet'auctions. The Morgue. Disponível em: «www.flavorwire. com/106955>. Acesso em 25 abr. 2011

para aquele Outro ali exposto, o nosso próximo, abandonado e esquecido no necrotério onde Andrés Serrano captura as imagens dos seus mortos. Observamos, então, que neste texto assumem a expressão de Outro tanto a imagem em si como o Outro ali exposto como imagem fotográfica.

As aproximações das implicações do conceito de vida nua de Agamben com 0 conceito de ética de Levinas podem ser pensadas mediante as imagens que nos apresenta Serrano em sua série. A vida nua agambeana refere-se às vidas relegadas ao estado de exceção que passa a ser a regra dentro da biopolítica e que foi muito além dos campos de concentração, assumindo também o controle sobre o direito de decidir quem devia viver e quem devia morrer dentro de uma concepção de que o diferente é "uma vida que não merece ser vivida". Nas imagens de Serrano, essas evidências são muito visíveis, pois suas imagens falam por si só da vida nua a partir do momento em que carregam naquelas os seus motivos. A aproximação do conceito da vida nua com o conceito ético levinasiano ocorre no momento em que as imagens dos mortos de Serrano despertam em nós um sentimento de respeito e de responsabilidade e, ao mesmo tempo, colocam-nos diante do abismo, que é o Outro, e também nos conduzem a pensar sobre o abismo que é a própria imagem, todas as questões pertinentes aos conceitos-chave dentro da ética de Levinas.

Partimos para a finalização desse texto com as palavras de Blanchot:

12 Tradução do nome da obra: Causa da morte desconhecida.

13 Tradução do nome da obra: Veneno de rato - suicídio II. 
Podemos sempre, certamente, recapturar a imagem e fazê-la servir à verdade do mundo; mas é que invertemos a relação que lhe é própria: a imagem torna-se, nesse caso, a seqüencia do objeto, o que vem depois dele, o que resta dele e permite ainda dispor dele quando dele nada resta, grande recurso, poder fecundo e razoável. (BLANCHOT, 1987, p. 262).

Vemos que a imagem funda um mundo existencial, que nos confere uma relação com esse mundo fora do habitual, como diz Blanchot, podemos fazer a imagem servir à verdade do mundo, mas isso seria inverter uma relação que the é própria. Assim, o que é próprio à imagem é ser esta outra noite que nos infere indagações, e temos que ela se torna ética não quando se ajusta à realidade do mundo, mas quando questiona essa realidade e a torna obscura, sussurrante. 
Referências Bibliográficas

> AGAMBEN, Giorgio. Homo Sacer: 0 poder soberano e a vida nua. Belo Horizonte: Editora UFMG, 2010.

> ARTIST'S Gallery. Andrés Serrano, American (1950-). Disponível em: <http://rogallery.com/Serrano_Andres/Andres_Serrano-Biography.htm>. Acesso em: 11 jun. 2011.

> BLANCHOT, Maurice. 0 espaço literário. Tradução de Álvaro Cabral. Rio de Janeiro: Rocco. 1987.

> CINTRA, Benedito Eliseu Leite. Emmanuel Lévinas e a idéia do infinito. Margem, São Paulo, n. 16, p.107-117, dez. 2002.

> DOUEK, Sybil Safdie. Paul Ricoeur e Emmanuel Lévinas, um elegante desacordo. São Paulo: Edições Loyola Jesuítas, 2011.

$>$ IMAGES of Death and Dying: Kathe Kollwitz, Gerhard Richter, Andres Serrano and Joel-Peter Witkin. Disponível em: «http://academic.evergreen.edu/curricular/imagingthebody/Handouts/DeathDyingLecture.pdf.. Acesso em: 11 jun. 2011.

> KONESKI, Anita Prado. Blanchot, Levinas e a arte do estranhamento. 2006. 231

f. Tese (Doutorado em Teoria Literária) - Universidade Federal de Santa Catarina, Florianópolis, 2006.

> LEVINAS, Emmanuel. Totalidade e infinito. Lisboa: Edições 70 Ltda, 1980.

> MELO, Nélio Vieira. A ética da alteridade em Emmanuel Levinas. Porto Alegre: EDIPUCRS. 2003.

Daisy Mary da Silva Proença, graduanda do Curso de Artes Plásticas da Universidade de santa Catarina (UDESC)

daisymspro@yahoo.com.br 